\title{
Impact of an Active Pharmacovigilance Program in a Third-Level Clinic in Barranquilla, Colombia
}

\author{
José Francisco Castro Bolívar ${ }^{1}$, Fernando Martínez-Martínez ${ }^{2}$ and Mónica Ferrit-Martin ${ }^{3}$ \\ 1. Faculty of Chemistry and Pharmacy, Universidad del Atlántico, Barranquilla, Colombia \\ 2. Research Group on Pharmaceutical Care from Universidad de Granada, Granada 18010, Spain \\ 3. Pharmacy Department, Hospital Universitario Virgen de las Nieves, Granada 18014, Spain
}

\begin{abstract}
The objective of this study is to assess the impact of APV (active pharmacovigilance) and PPV (passive pharmacovigilance) by detection of ADEs (adverse drug events), through PIs (pharmaceutical interventions). Authors have used observational pre-post intervention study. Dader methodology was used in 123 patients with data obtained from medical records and pharmaceutical interview. Detection of ADE was made by direct observation and laboratory tests, with statistical significance 0.05 . In PPV, 47 ADEs were detected: nausea, vomiting, skin rash and skin redness. In APV, 100 ADEs are presented, similar to those described in the PPV, in which Dipyrone produced $26.2 \%$. The causes of DRPs (drug related problems) were: probability of adverse events $36 \%$, personal characteristics $30 \%$, and dose regimen and/or inadequate duration $22 \%$. Out of 127 PIs performed, $91.34 \%$ were accepted and resolved. The patient satisfaction rate was $82.7 \%$ for APV and doctor satisfaction $90.4 \%$ with high impact, surpassing the $80 \%$. The impact of APV was $93.6 \%$ and 53\% in PPV for PIs and ADEs. PIs were performed to the ADEs with a high percentage of accepted and solved ones. Evaluation of satisfaction of patients and doctors in APV had a high impact. The assessment of APV generated a high impact on compliance and PPV a low one.
\end{abstract}

Key words: Impact, PI (pharmaceutical intervention), ADE (adverse drug event).

\section{Introduction}

Pharmacotherapy is a pivotal tool for the management and stabilization of a great variety of pathologies. In order to be approved, medicaments require several studies, not only to show efficacy, but also to determine its safety and to guarantee, that way, its use previous to commercialize it [1]. However, medicaments are not free of harmful and not on purpose results, called ADR (adverse drug reaction).

In 2,000, a report estimated that the total cost of preventable ADRs in the US, including the loss of family wages and production, handicap and health expenses, was within 17 29 thousand million dollars [2]. That is the cause why, presently, the importance of detecting, assessing, understanding and preventing

Corresponding author: José Francisco Castro Bolívar, master, research fields: pharmacotherapy follow-up, pharmacovigilance, drug utilization studies and health education. adverse event of medicaments and any other problem related to them, defined as pharmacovigilance, has become one of the main tools for quality in health centers.

The WHO (World Health Organization) has proposed a constant follow-up to all medicaments in the market. Nevertheless, a non-minor percentage of ADRs might not be reported or informed. In fact, several studies showed that only $6 \sim 10 \%$ of all ADRs at the country level are reported [3].

The prevalence of ADR in ambulatory population in Colombia is not accurately known, however, a national study showed that it might be in $6.4 \%$ [4].

This is why a pharmacovigilance program is a pivotal strategy to detect and prevent ADRs effectively and to influence positively on the quality of the patient's assistance [5]. The contribution of pharmaceutical professionals to volunteer notification of ADRs promote a higher number of reported ADRs, 
reaching in some cases, responsibility for $40 \%$ of the yearly reports [6]. However, there are not published studies in Colombia that show the importance of the role of the pharmaceutical professional in an active pharmacovigilance system.

Drugs are causing ADEs (adverse drug events), therefore, they have been studied in several countries. Due to their frequency and for increasing morbidity and mortality, they are a public health problem [7]. WHO, in 2002, established the guidelines and criteria for building policies to prevent, identify and minimize ADEs [8]. Consistent with this global trend, the IBEAS study (Ibero American Study of Adverse Events) in which Colombia, Costa Rica, Peru and Argentina unite to identify the ADEs, to establish their prevalence and characteristics, and to develop their own methodologies, internationally comparable [9].

Salas et al. [10] reported several ADEs producing hospital admissions, ranging from $2.4 \%$ to $12 \%$, are related to ADR. Additionally, 5 8 \% of the hospitalized patients presented with serious ADR and 0.05 0.44, were fatal. ADR can be serious. Approximately $1 \%$ of patients die as a result thereof. While some ADR can be unpredictable, there is evidence that $62.3 \%$ of these are potentially preventable [11].

Some studies show a frequency of ADE in hospitalized Colombian patients ranging between 1.2\% and $45 \%[12,13]$. The variability of the figures depends on several factors, such as detection method used, APV (active pharmacovigilance) or PPV (passive pharmacovigilance).

The essence of PV (pharmacovigilance) is to identify ADE, analyze them and generate prevention strategies. Currently, they are a public health problem with an emerging focus on our society. Pharmacists provide pharmaceutical care, detecting potential ADE, for safe patient care, compliance with hospital policies and as a source of drug information to nurses, doctors and other health professionals [14].

According to the National Pharmacovigilance
Program in Colombia, out of the 403 ADR reports in February 2015, a total of 566 ADRs were registered (1.4 ADEs for each report), of which 345 (61\%) were classified as serious and $221(39 \%)$ as not serious. The system with more ADEs was skin alterations and annexes with 123 ADRs, followed by general alterations with 61 ADRs, unlike January reporting respiratory system disorders. It is evident that the ADEs classified as possible have a higher proportion [15].

This study is a pioneer in the city of Barranquilla and allows us to approach an objective reality in the context of patient safety. The specific objectives of the study were to characterize the development of the PPV implemented, to design and to implement the APV program, and to assess the impact of APV and the pharmaceutical interventions in a third-level clinic in Barranquilla, Colombia.

\section{Method}

The design of this study was observational, pre-post intervention, taking 12 months (June 2013 to June 2014). There was a first retrospective phase to analyze the ADE in the PPV and then a prospectively one, after implantation of the APV. Dader methodology [16] was used to evaluate the impact of PI (pharmaceutical intervention) made in a clinic of 194 beds. 123 patients, who met the inclusion criteria: age over 18, polymedicated, with ADE risk, and who signed informed consent, were included. A simple randomized sampling was performed to patients who met criteria for inclusion/exclusion to establish the number of patients.

In the PPV, the study variables were: gender (male, female), average age (years), average number of prescribed medications, hospital stay, percentage of ADE (\%), ADE diagnosis according to physiological system and drugs involved as ATC (anatomical, therapeutic, chemical) classification, causality (proved, probable, possible and doubtful), gravity (mild, moderate, severe and lethal), preventability (avoidable, 
not avoidable), ADE associated with medicines, and drugs used in treatment. In the APV program, the following variables were also included: degree of acceptance (accepted, not accepted) meeting the PI (high, moderate and low), impact of programs PPV and APV (met, not met), negative results related to drug of intervention or DRP (drug related problems) (need, effectiveness, safety). The degree of acceptance of the PIs was obtained by the equation:

Degree of acceptance $=($ Total accepted and resolved $\mathrm{PI}) /($ Total $\mathrm{PI}) \times 100$

Total satisfaction of patients and relatives was measured by a questionnaire validated by Lores et al. [17], consisting of 11 open and closed questions. The impact of satisfaction of the intervention was determined by the following formula:

Impact of satisfaction $=($ Total patients, relatives, physicians satisfied)/(Total patients, relatives, physicians surveyed) $\times 100$

PI and satisfaction of patients and physicians were classified in high impact ( $>80 \%)$, average (60 80\%) and low $(<60 \%)$. The impacts of APV and PPV programs were evaluated through a questionnaire consisting of 47 questions that measured eight items, the possible answers for each question were: "meets" and "not met".

To detect DRP general patient data, drugs given, adherence to prescribed treatments, altered results of laboratory, habits, allergies to certain drugs and/or food, physical activity, diseases, such as kidney failure, liver failure, altered potassium values and other factors that modify the patient/drug relationship were assessed. Choice and justification of the use of drugs were also assessed, so necessary DRPs were determined. Effectiveness DRPs were reviewed from the doses used and the evolution of patients, and safety DRPs were detected through the extensive search in the clinical history of the occurrence of some ADE thoroughly analyzing the different treatments, identifying potential drug interactions, pharmaceutical interview and assessment of the status.
Detection of diagnostic of ADE was conducted prior to training of health personnel in the FOREAM (form of adverse drug events) by the INVIMA (National Institute of Food and Drug Monitoring) [18]. The cause-effect (causality) in the individualization of drug associated with an ADE was defined according to conventional classification proposed by Seidl et al. [19], which takes four discrete categories: proved, probable, possible and doubtful. The standardized Naranjo et al. [20] algorithm was used to establish causality. Gravity was established according to WHO classification: mild, moderate, severe and lethal. To evaluate the preventability, the questionnaire validated by Baena et al. [21], which determines the degree of preventability of NOM (negative outcome associated with medication), which consists of 13 questions applied to each NOM was used. The affirmative answer to one or more of these questions implies that the NOM is avoidable. More than an affirmative answer will not be a greater preventability.

The study used Dader methodology and focused on the detection and analysis of ADEs in hospitalized patients. We used an Excel database retrospectively with variables in the PPV characterization. The APV implementation was performed by the pharmaceutical researcher in hospitalization in order to obtain information about patients and health professionals, on the possible presence of ADE. When suspecting an ADE, medical history was reviewed and it was assessed by a doctor.

\section{Results}

The study results were statistically analyzed using SPSS Version 20. A descriptive analysis with central tendency measures and dispersion for quantitative variables and relative frequencies for qualitative variables was conducted. Student's t-test was applied to compare average ages, while the test $\mathrm{W}$ by Mann Whitney was used to compare the median of hospital stays. Statistical significance 0.05 was established.

The study was approved by the ERC (Ethics 
Committee) of the third-level clinic, assessing compliance with GCP (good clinical practice), established in the Declaration of Helsinki and the guidelines of the ICH (International Conference on Harmonisation) for GCPs [22]. The law of personal data protection was applied.

As shown in Table 1, the average age of the population, in PPV and APV, was $49.89 \pm 18.01$ and $53.17 \pm 18.19$ years, respectively. In the PPV, mixed race ethnic group represented $100 \%$. In APV, mixed race ethnic group represented 93.7\%, and Afro-Colombian group 5.3\%. In PPV, 53.2\% were men and $46.8 \%$ women. In APV, $61.79 \%$ were women and $38.21 \%$ were men.

Table 2 shows that, in APV, the major systems affected by ADE are dermatologic $31 \%$ and digestive and metabolism $30 \%$. In PPV, we find the anti-infective in general for systemic use $(42.5 \%)$. The main suspected of causing ADE drugs were dipyrone $26.2 \%$ and vancomycin $16.7 \%$. In the PPV, the drugs used in the treatment of ADE were hydrocortisone $61.1 \%$ and $47.1 \%$ in the APV.

Table 3 shows the causality in the PPV: probable $61.7 \%$ and possible $38.3 \%$. In APV: probable 52\% defined $28 \%$, possible $15 \%$ and doubtful $5 \%$. According to seriousness, in APV, the figures are: moderate $49 \%$, mild $39 \%$ and serious $12 \%$. In PPV, moderate $72.3 \%$ and mild $27.7 \%$. In APV, ADEs were preventable $42 \%$ and non-preventable $58 \%$. In PPV: preventable $76.6 \%$ and non-preventable $23.4 \%$. The ADEs in the APV were diarrhea $31.9 \%$, nausea and vomiting $12 \%$, and skin rash $11.1 \%$. In PPV: nausea and vomiting $17 \%$, rash $12.8 \%$, and itching $12.8 \%$.

Table 4 shows APV with the most common causes of DRP: probability of adverse effect $36 \%$; personal characteristics $30 \%$; dose, regimen and/or inadequate duration $22 \%$. According DRPs, they generated an impact on the need of $7.9 \%$, efficiency $13.5 \%$, and safety $78.1 \%$ of drug treatments. Out of the $127 \mathrm{PI}$ made, 116 (91.3\%) were accepted and resolved, 3.94\% were not accepted but resolved, and $4.72 \%$ were neither accepted nor resolved.

Table 5 shows the altered results of laboratory: creatinine, PT (prothrombin time) and alkaline phosphatase $50 \%, 15.5 \%$ and $8.6 \%$, respectively, as an indicator of $\mathrm{ADE}$.

\section{Discussion}

Differences in PV programs were found, as well as on security and detection methods due to the fact that they are two different populations. Underreporting is shown in PPV. PPV results were very similar to the referenced studies [23]. In the PPV, ADEs in men predominate, while in APV women predominate,

Table 1 Demographic characteristics of the population, according to gender, age range, race, medicaments per patient and hospital stay in PPV and APV.

\begin{tabular}{lllll}
\hline Items & & PPV Before $(n=47)$ & APV After $(n=87)$ & $p$ \\
\hline \multirow{3}{*}{ Gender and age } & Woman & $22(46.81 \%)$ & $57(65,5)$ & - \\
& Man & $25(53.19 \%)$ & $30(34,5)$ & - \\
& Age (years) media + SD & $49.89 \pm 18.01$ & $51.95 \pm 18.32$ & 0.003 \\
\hline \multirow{4}{*}{ Race } & Mixed-race woman & $22(48.81)$ & $55(63.22)$ & - \\
& Mixed-race Man & $25(53.19)$ & $28(32.18)$ & - \\
& African Colombian Man & $-^{\mathrm{a}}$ & $2(2.3)$ & - \\
& African Colombian woman & $-^{\mathrm{a}}$ & $2(2.3)$ & - \\
& Medicaments per patient, media + SD & $16.5 \pm 4.7$ & $16.79 \pm 10.96$ & 0.433 \\
\hline
\end{tabular}

${ }^{\mathrm{a}}$ Not reported;

$n$ : sample size;

$p: p$ value or critical level indicating that the affirmation is statistically significant or not;

SD: standard deviation. 
Table 2 Distribution of adverse events per notified medicament, according to affected systems, taking into account ATC code or anatomical, therapeutic, chemical classification system of WHO.

\begin{tabular}{|c|c|c|}
\hline System/organ/manifestations & PPV Before $(n=47)$ & $\operatorname{APV} \operatorname{After}(n=100)$ \\
\hline Digestive system and metabolism (A) & $8(17.02)$ & $30(30)$ \\
\hline Dermatológical medicaments (D) & $-^{\mathrm{a}}$ & $31(31)$ \\
\hline General antiinfective for systemic use (J) & $20(42.55)$ & $3(3)$ \\
\hline Nervous system (N) & $6(12.77)$ & $14(14)$ \\
\hline Blood and hematopoyetic organs (B) & $2(4.26)$ & $5(5)$ \\
\hline Cardiovascular system (C) & $3(6.38)$ & $4(4)$ \\
\hline Antineoplasicand inmune modulators agents (L) & $7(14.89)$ & $-^{\mathrm{a}}$ \\
\hline Respiratory system (R) & $-^{\mathrm{a}}$ & $7(7)$ \\
\hline $\begin{array}{l}\text { Others: genital urinary system and sexual hormones } 1(\mathrm{G}) \text {, systemic hormonal } \\
\text { preparation, excluding sexual hormones }(\mathrm{H}) \text { and Muscle skeletal system }(\mathrm{M})\end{array}$ & $1(2.13)$ & $6(6)$ \\
\hline Medicaments involved in evitable ADE & PPV Before $(n=36)$ & APV After $(n=42)$ \\
\hline Dipirone & $2(5.56)$ & $11(26.19)$ \\
\hline Vancomicin & $6(16.67)$ & $3(7.14)$ \\
\hline Ceftriaxone & $2(5.56)$ & $4(9.52)$ \\
\hline Asparagine & $5(13.89)$ & $-{ }^{a}$ \\
\hline Tramadol & $1(2.78)$ & $3(7.14)$ \\
\hline Others & $20(55.56)$ & $21(50)$ \\
\hline Medicaments used in the treatment of ADE & PPV Before $(n=18)$ & APV After $(n=34)$ \\
\hline Hydrocortisone $100 \mathrm{mg}$ (7), de $300 \mathrm{mg}$ (2), de $200 \mathrm{mg}$ (1) cream $1 \%$ & $11(61.11)$ & $16(47.06)$ \\
\hline Metoclopramide $10 \mathrm{mg}$ & $2(11.11)$ & $6(17.65)$ \\
\hline Bisacodilo $5 \mathrm{mg}$ & $2(11.11)$ & $2(5.88)$ \\
\hline Others & $3(16.67)$ & $10(29.41)$ \\
\hline
\end{tabular}

${ }^{\mathrm{a} N o t}$ reported.

Table 3 Variables relation between causality, seriousness, preventability and medicaments causing NRMs (negative results associated with medicaments).

\begin{tabular}{lll}
\hline Causality & PPV Before $(n=47)$ & APV After $(n=100)$ \\
\hline Probable & $29(61.70)$ & $52(52)$ \\
Possible & $18(38.30)$ & $15(15)$ \\
Defined & $-^{a}$ & $28(28)$ \\
Doubted & $-^{\mathrm{a}}$ & $5(5)$ \\
\hline Seriousness & PPV Before $(n=47)$ & APV After $(n=100)$ \\
\hline Moderate & $34(72,34)$ & $49(49)$ \\
Mild & $13(27,66)$ & $39(39)$ \\
Serious & $-{ }^{a}$ & $12(29)$ \\
\hline Preventability & PPV Before $(n=47)$ & APV After $(n=100)$ \\
\hline Preventable & $36(76.6)$ & $42(42)$ \\
Not preventable & $11(23.4)$ & $58(58)$ \\
\hline Medicaments causing ADE & PPV Before $(n=47)$ & APV After $(n=100)$ \\
\hline Nauseas and vomits & $8(17.02)$ & $12(12)$ \\
Skin rash & $6(12.77)$ & $11(11)$ \\
Redness & $3(6.38)$ & $10(10)$ \\
Itching & $6(12.77)$ & $4(4)$ \\
\hline
\end{tabular}


(Table 3 continued)

\begin{tabular}{lll}
\hline Medicaments causing ADE & PPV Before $(n=47)$ & APV After $(n=100)$ \\
\hline Constipation & $4(8.51)$ & $5(5)$ \\
Diarrhea & $-^{\mathrm{a}}$ & $5(5)$ \\
Emesis & $-^{\mathrm{a}}$ & $5(5)$ \\
Tachycardia & $2(4.26)$ & $2(2)$ \\
Seizures & $-^{\mathrm{a}}$ & $4(4)$ \\
Dyspnea & $-^{\mathrm{a}}$ & $4(4)$ \\
Others & $18(38.30)$ & $38(38)$ \\
\hline
\end{tabular}

${ }^{\mathrm{a}}$ Not reported.

Table 4 Variables related to NRM types and PI.

\begin{tabular}{lll}
\hline Causes related to medicaments & PPV Before ${ }^{\mathrm{a}}$ & APV After $(n=100)$ \\
\hline Probability of adverse effects & $-^{\mathrm{a}}$ & $36(36)$ \\
Personal characteristics & $-^{\mathrm{a}}$ & $30(30)$ \\
Dose, regimen and/or inadequate duration & $-^{\mathrm{a}}$ & $22(22)$ \\
Wrong administration of medicaments & $-^{\mathrm{a}}$ & $6(6)$ \\
Non-compliance Interactions & $-^{\mathrm{a}}$ & $4(4)$ \\
Others & $-^{\mathrm{a}}$ & $2(2)$ \\
\hline NRM & PPV Before $^{\mathrm{a}}$ & APV After $(n=100)$ \\
\hline Effect of unnecessary medicament accepted and resolved & $-^{\mathrm{a}}$ & $3(2.36)$ \\
Untreated health problem accepted and resolved & $-^{\mathrm{a}}$ & $7(5.51)$ \\
Quantitative ineffectiveness accepted and resolved & $-^{\mathrm{a}}$ & $8(6.30)$ \\
Non-quantitative ineffectiveness accepted and resolved & $-^{\mathrm{a}}$ & $7(7.09)$ \\
Non-quantitative insecurity accepted and resolved & $-^{\mathrm{a}}$ & $89(70.8)$ \\
Non-quantitative insecurity accepted and not resolved & $-^{\mathrm{a}}$ & $5(3.94)$ \\
Non-quantitative insecurity not accepted, not resolved & $-^{\mathrm{a}}$ & $6(4.72)$ \\
\hline PI & PPV Before $^{\mathrm{a}}$ & APV After $(n=127)$ \\
\hline Total interventions accepted and resolved & $-^{\mathrm{a}}$ & $116(91.34)$ \\
Total interventions not accepted and resolved & $-^{\mathrm{a}}$ & $5(3.94)$ \\
Total interventions not accepted and not resolved & $-^{\mathrm{a}}$ & $6(4.72)$ \\
\hline Not reported & &
\end{tabular}

${ }^{\mathrm{a} N o t}$ reported.

Tabla 5 Frequency of altered lab results, as an indicator of adverse drug events detection.

\begin{tabular}{lll}
\hline Alterated lab Results & PPV Before ${ }^{\mathrm{a}}$ & APV After $(n=58)$ \\
\hline Creatinine & $-^{\mathrm{a}}$ & $29(50)$ \\
PT & $-^{\mathrm{a}}$ & $9(15.5)$ \\
Phosphatase alkaline & $-^{\mathrm{a}}$ & $5(8.6)$ \\
AST (aspartate aminotransferase) & $-^{\mathrm{a}}$ & $4(6.9)$ \\
Potasium & $-^{\mathrm{a}}$ & $3(5.2)$ \\
Platelets & $-^{\mathrm{a}}$ & $2(3.4)$ \\
Albumina & $-^{\mathrm{a}}$ & $2(3.4)$ \\
INR (international normalized ratio) & $-^{\mathrm{a}}$ & $2(3.4)$ \\
ALT (alanina aminotransferase) & $-^{\mathrm{a}}$ & $2(3.4)$ \\
\hline
\end{tabular}

${ }^{\mathrm{a}}$ Not reported. 
coinciding with the reported in other studies [24, 25]. The study of Sriram et al. [26] showed that $61 \%$ of the patients were male while in the PPV they were 53.2\%. These results match Tribiño et al. [27], who conducted a study with gender differences, being male higher in PPV. This difference is probably due to bias in the study. Soldin et al. [28] disclosed that the predisposition to ADRs between men and women is due to the differences in the pharmacokinetics and pharmacodynamics of genres. PPV exceeds the APV in the mixed ethnicity. The average age of the population was higher in APV. The average drug results are close in both programs. Hospital stay is higher in the PPV.

When comparing the ages of the groups with Kolmogorov-Smirnov normality test, it was observed that both populations have a normal behavior and their variations are statistically equal $(p=0.771)$. Due to this, their averages were compared with the Student's t-test, obtaining a $p$ value 0.00 , which indicates a statistically important difference between them, with a confidence interval of $95.0 \%$.

Hospital stay in PPV does not come from a normal population $(p=0.0462)$, while in APV, it does $(p=0.0633)$. When comparing their variations with Fisher test, they are not the same $(p=0)$. With $\mathrm{W}$ test by Mann Whitney, a p value 0.205 is resulted. This indicates no major statistical difference between the medians, with a confidence interval of $95 \%$.

The most affected system in APV was dermatologic (31\%), similar to the study of Marques et al. [29], in the skin $(21 \%)$. In a study in Saudi Arabia, skin ADEs fluctuate between $34.1 \%$ and $68.8 \%$ [30], a result close to that obtained in this study.

In PPV, the probable and possible causality was $61.7 \%$ and $38.3 \%$, respectively. In APV, the probable one was lower with $52 \%$, and the possible one $15 \%$. Regarding seriousness, in PPV moderate were higher with $72.3 \%$, while in the APV they were 49\%. No ADE was fatal. Preventable ADEs were higher in the PPV: $76.3 \%$, similar to those of McDonnell and Jacobs [11] with $62.3 \%$. Non-preventable were higher in the APV with $58 \%$. Nausea and vomiting were the higher ADE with $17 \%$ in PPV and $12 \%$ in APV.

PI performed generated an impact on the need $(\mathrm{N})$ of $7.9 \%$, effectiveness (E) $13.5 \%$ and safety (S) $78.1 \%$, close to those reported by Danneris et al. [31] of $\mathrm{N}$ (17.5\%), E (31.4\%) and S (51.1\%) [31]. Serious ADE were $12 \%$ in the APV near that reported in the meta-analysis conducted in the US by Lazarou et al. [32] and Motola et al. [33], which was determined by $6.7 \%$ and $4.9 \%$, respectively $[32,33]$. The research does not consider determine the factors that favor the emergence of an ADE, but the number of pathologies present may be a predisposing factor [34].

Variability is wide in different studies evaluating the percentage of preventable ADEs 18.7 73.2\% [35]. Other research indicates that more than half of all ADE were preventable [36].

91.3\% of PI made were accepted and approved, as a result of the PI, pharmacovigilance bulletins were published, to socialize them with the health team, and to reduce avoidable ADE. A tendency to reduce ADE was observed. PI generated an impact, showing a positive result of the APV and the benefits to the patient in his pharmacotherapy. Many studies have reported the importance of clinical pharmacist in the reporting and prevention of problems related to drugs [37, 38].

Assessment of APV had a high impact on compliance $(93.6 \%)$ and PPV an impact of non-compliance $(53 \%)$. The level of satisfaction of patients and/or relatives was $82.7 \%$ and $90.4 \%$ of physicians in the APV classified with an impact over $80 \%$.

Differences are observed when comparing PPV and APV. In PPV, the affected system was infections with 42.5\%. In APV, it was skin with $31 \%$. Drugs to generate $\mathrm{ADE}$ in the PPV were vancomycin and asparaginase with $16.7 \%$ and $13.9 \%$, respectively. In the APV, it was dypirone with $26.2 \%$. According causality in PPV and APV, close values are observed (61.1\% and 52\%, respectively) as probable. Possible 
causality differs in both programs. PPV is classified only as probable and possible, while in APV, defined and doubtful are also included. According to seriousness, in PPV, moderate is higher (72.3\%) and in APV 49\%. There are more serious ADEs in the APV (12\%) than in PPV. In PPV, preventability was higher with $76.6 \%$ while in APV it was $42 \%$. In APV, a higher percentage of non-avoidable (58\%) was found, while in PPV it was $23.4 \%$. Nausea and vomiting and skin rash were the highest percentage of ADE in both programs. Hydrocortisone is indicated in the treatment of ADE in both programs being higher in the PPV. Metoclopramide is slightly increased in the APV compared with the PPV. The impact factor of the PI was $93.6 \%$, a result which coincides with the studies of congestive heart failure reported by Lores et al. [17] with an impact factor of $98.6 \%$ and endocrinology in the city of Bayamo Granma-Cuba [31] at a rate of $80.3 \%$ impact.

Within the limitations found in this study, assessments of causality of ADE require a pre-exposure of the suspected drug and clinical reappearance event, for the maximum degree of imputability [39].

\section{Conclusions}

The present study identified ADE in PPV and APV. Records found in PPV were incomplete, preventing the researchers from making a deep analysis of ADE. In this sense, the implementation of an APV system in a third-level clinic, performed by a pharmaceutical professional program, increases the detection of ADE, decreases the sub-notification of PPV and promotes its prevention. In APV, more preventable ADEs than non-preventable ones were detected. Regarding causality, probable and defined ones represented the higher percentage. Moderate and mild seriousness was higher, too. According to NRMs, performed and accepted interventions generated a higher percentage of security. Out of the interventions generated, a high percentage of accepted and solved were generated. The level of satisfaction on the evaluation by patients and/or relatives, and doctors resulted on a high impact, over $80 \%$. Evaluation of the APV program had a high impact. The high percentage of ADE found might be avoided by carrying out other studies to measure the effect of PV follow-up, and by going deeper into the possible risk factors as an strategy for prevention, detection and resolution of NRMs. The actual impact of PV follow-up might be known.

\section{References}

[1] Marovac, J. 2001. "Investigation and development of new drugs: from the molecule to drug." Rev. Med. Chile 129 (1): 99-106.

[2] Zolezzi, M., and Parsotam, N. 2005. "Adverse Drug Reaction Reporting in New Zealand: Implications for Pharmacists." Ther. Clin. Risk Manag. 1 (3): 181-8.

[3] Ghosh, S., Ali, S., Chhabra, L., Prasad, C., and Gupta, A. 2010. "Investigation of Attitudes and Perception of Medical Practitioners on Adverse Drug Reaction Reporting-A Pilot Study.” T. Ph. Res. 3 (6): 1-9.

[4] Calderón, C. A., and José, J. G. 2008. "Adverse Drug Reactions as the Reason for a Service Priority Attention." Rev. Public health 10 (2): 315-21.

[5] López-González, E., Herdeiro, M. T., and Figueiras, A. 2009. "Determinants of Under-Reporting of Adverse Drug Reactions." Drug Saf. 32 (1): 19-31.

[6] Van Grootheest, K., Olsson, S., Couper, M., and De Jong-Van Den Berg, L. T. 2004. "Pharmacists' Role in Reporting Adverse Drug Reactions in an International Perspective." Pharmacoepidemiol. Drug Saf. 13 (7): 457-64.

[7] Camargo, A. E., Moreira, A. M., Miasso, A. I,. De Bortoli, S. H. 2011. "Adverse Events Caused by Medicaments in a Watch Hospital in Goias State." Latin American revisionEnfermagen 19 (2): 1-9. Accessed June 25, 2015. http://www.eerp.usp.br/rlae.

[8] WHO (World Health Organization). 2002. The World Health Report 2002: Reducing Risks, Promoting Healthy Life. Geneve: WHO, 7-14.

[9] Aranaz, J. M., Remón, C. A., Burillo, J. V., and López, P. R. 2005. "National Study about the Adverse Effects Associated to Hospitalization.” ENEAS, Madrid, Ministry of Health and Consume. Accessed December 16, 2015. http://www.msc.es/organizacion/sns/planCalidadSNS/pdf /excelencia/opsc_sp2.pdf.

[10] Salas, S. G., Pérez, M. E., Meléndez, S. G., and Castro, L. I. 2012. "Adverse Reactions to Medicaments Related to Hospital Admissions and Stay: Systematic Revision 
2000-2011." Rev. Mex. Ciencias Farm. 43 (3): 19-35.

[11] McDonnell, P. J., and Jacobs, M. R. 2002. "Hospital Admissions Resulting from Preventable Adverse Drug Reactions.” Ann. Pharmacother. 36 (9): 1331-6.

[12] Vallejos, A. 2007. "Adverse Reactions to Antibiotics in an Intensive Pediatric and Neonatal Care Unit in Bogota." Biomédica 27: 66-75.

[13] Bustamante, C., Calderón, C., Castillo, I., Cifuentes, P., and Ramírez, J. 2007. "Adverse Reactions to Medicaments in Adult Patients Hospitalized in University Clinic Teletón, Bogota." Phamacovigilance Report from INVIMA (National Institute for Medicaments and Food Surveillance) 18: 8-13.

[14] Katherine, B., Veverka, A., Krick, E. S. 2014. "Improving Pharmacist Documentation of Clinical Interventions through Focused Education." Am. J. Health-Syst. Pharm. 71: 1303

[15] INVIMA (National Institute for Medicaments and Food Surveillance). 2015. "PharmacoSafety Report." INVIMA. Accessed July 18, 2015. https://www.invima.gov.co/ images/pdf/farmacovigilancia_alertas/boletines/2015/FV _Farmaseguridad_Vol_4_N\%201_2015.pdf.

[16] Hernández, D. S., Castro, M. M. S., and Dáder, M. J. F. 2007. Dader Methodology Programme. Dader Pharmacotherapeutic Follow Up Guide. 3rd ed. Granada: Grupo de Investigación en Atención Farmacéutica (CTS-131). Universidad de Granada.

[17] Lores, D. D., Lazo, R. Y., Bermúdez, C. I., and Zúñiga, M. A. 2011. "Impact of a Pharmacotherapeutic Follow Up Service Developed for 30 Patients with Congestive Heart Failure.” Mexican Journal of Pharmaceutical Sciences 42 (2): 45-53.

[18] INVIMA. "Pharmacovigilance." In Form for Suspected Adverse Drug Events. FOREAM. Code: F232-PM02-IVC. Version 2. INVIMA. Accessed October 28, 2014. https://www.invima.gov.co/index.php?option=com_conte $\mathrm{nt} \&$ view $=$ article $\& \mathrm{id}=3613 \% 3$ Aformatos $\&$ catid $=191 \% 3 \mathrm{~A}$ farmacovigilancia\&Itemid $=323$.

[19] Seidl, L. G., Thornton, G. F., and Smith, J. W. 1966. "Studies on the Epidemiology of Adverse Drug Reactions." Johns Hopkins Med J. 119: 299-315

[20] Naranjo, C. A., Busto, U., Sellers, E. M., Sandor, P., Ruiz, I., Roberts, E. A., et al. 1981. "Method for Estimating the Probability of Adverse Drug Reactions." Clin. Pharmacol. Ther. 30: 239-45.

[21] Baena, M. I., Marín, R., Martínez Olmos, J., Fajardo, P., Vargas, J., and Faus, M. J. 2002. "New Criteria to Determine Avoidability of Problems Related to Medicaments. An Updated Revision from the Experience with 2558 People." Pharm. Care Esp. 4: 393-6.

[22] Zion, D., Gillam, L., and Loff, B. 2000. "The Declaration of Helsinki, CIOMS and the Ethics of Research on
Vulnerable Populations." Nat. Med. 6: 615-7.

[23] López-González, E., Herdeiro, M. T., and Figueiras, A. 2009. "Determinants of Under-Reporting of Adverse Drug Reactions." Drug Saf. 32: 19-31.

[24] Mannesse, C. K., Derkx, F. H., De Ridder, M. A., ManIn't Veld, A. J., and Van Der Cammen, T. J. 2000. "Contribution of Adverse Drug Reactions to Hospital Admission of Older Patients." Age Ageing 29: 35-9.

[25] Mjörndal, T., Boman, M. D., Hägg, S., Bäckström, M., Wiholm, B. E., Wahlin, A., et al. 2002. "Adverse Drug Reactions as a Cause for Admissions to a Department of Internal Medicine." Pharmacoepidemiol. Drug Saf. 11 (1): 65-72.

[26] Sriram, S., Ghasemi, A., Ramasamy, R., Devi, M., Balasubramanian, R., Ravi, T. K., et al. 2011. "Prevalence of Adverse Drug Reactions at a Private Tertiary Care Hospital in South India." J. Res. Med. Sci. 16: 16-25.

[27] Tribiño, G., Maldonado, C., Segura, O., and Díaz, J. 2006. "Direct Expenses and Clinical Aspects of Adverse Reactions to Drugs in Internal Medicine Hospitalized Patients in a Third Level Institution in Bogota." Biomédica 26: 31-41.

[28] Soldin, O. P., Chung, S. H., and Mattison, D. R. 2011. "Sex Differences in Drug Disposition." J. Biomed. Biotechnol. 2011: 187103.

[29] Marques, J., Ribeiro-Vaz, I., Pereira, A. C., and Polónia, J. 2014. A Survey of Spontaneous Reporting of Adverse Drug Reactions in 10 Years of Activity in a Pharmacovigilancecentre in Portugal." Int. J. Pharm. Pract. 22 (4): 275-82.

[30] Khan, L. M., Al-Harthi, S. E., Saadah, O. I., Al-Amoudi, A. B., Sulaiman, M. I., and Ibrahim, I. M. 2012. "Impact of Pharmacovigilance on Adverse Drug Reactions Reporting in Hospitalized Internal Medicine Patients at Saudi Arabian Teaching Hospital." Saudi Med. J. 33 (8): 863-8.

[31] Danneris, L. D., Yaily, L. R., Isis, B. C., and Aurora, Z. M. 2011. "Impact of a Pharmacotherapeutic Follow-Up Service Developed for Patients with Congestive Heart Failure." Mexican Journal of Pharmaceutical Sciences 42 (2): 45-53.

[32] Lazarou, J., Pomeranz, B. H., and Corey, P. N. 1998. "Incidence of Adverse Drug Reactions in Hospitalized Patients: A Meta-analysis of Prospective Studies." JAMA 279 (15): 1200-5.

[33] Motola, D., Melis, M., Lo Bianco, S., Buccellato, E., Biagi, C., and Vaccheri, A. 2014. "Ten Years of Pharmacovigilance in Italy: The Experience of Emilia-Romagna Region in the Monitoring of Drug's Safety Profile." Expert Opin. Drug Saf. 13 (7): 867-73.

[34] Passarelli, M. C., Jacob-Filho, W., and Figueras, A. 2005. 
"Adverse Drug Reactions in an Elderly Hospitalised Population: Inappropriate Prescription is a Leading Cause." Drugs Aging 22 (9): 767-77.

[35] Kanjanarat, P., Winterstein, A. G., Johns, T. E., Hatton, R. C., González-Rothi, R., and Segal, R. 2003. "Nature of Preventable Adverse Drug Events in Hospitals: A Literature Review." Am. J. Health-Syst. Pharm. 60: 1750-9.

[36] Davies, E. C., Green, C. F., Taylor, S., Williamson, P. R., Mottram, D. R., and Pirmohamed, M. 2009. “Adverse Drug Reactions in Hospital In-Patients: A Prospective Analysis of 3,695 Patient-Episodes." PLOS ONE 4 (2): e4439.

[37] Klopotowska, J. E., Kuiper, R., Van Kan, H. J., De Pont A.
C., Dijkgraaf, M. G., Lie-A-Huen, L., et al. 2010. "On-ward Participation of a Hospital Pharmacist in a Dutch Intensive Care Unit Reduces Prescribing Errors and Related Patient Harm: An Intervention Study." Crit. Care 14 (5): 1-11.

[38] Crowther, D. M., Buck, M. L., McCarthy, M. W., Barton, V. W. 2011. "Improving Pediatric Adverse Drug Event Reporting through Clinical Pharmacy Services.” J. Pediatr. Pharmacol. Ther. 16 (4): 285-90.

[39] PAHO (Pan American Health Organization). 2010. Pharmacovigilance Good Practice for the Americas. Washington, D.C.: PAHO. Accessed November 12, 2015. http://apps.who.int/medicinedocs/documents/s18625es/s18 625es.pdf. 